\title{
Expectations and Effectiveness Using CD-ROMs: What Do Patrons Want and How Satisfied Are They?
}

\author{
Cheryl A. McCarthy, Sylvia C. Krausse, and \\ Arthur A. Little
}

As academic libraries wrestle with how to provide more CD-ROMs and more online remote access to databases to keep pace with demands, they first need to evaluate the effectiveness of their current services. This study identifies students' preferences and effectiveness using CDROMs and assesses the whole CD-ROM environment at one university library. A questionnaire was used to ask students their preferences, confidence levels, skills, and training in searching CD-ROM databases, as well as their satisfaction with CD-ROM services (see the appendix). Analyses of the data revealed that users are satisfied and prefer CDROM databases over the print indices. Although students indicated they are confident searching, they admitted that they need to know basic search strategies and that they want more personal assistance, handson training, and remote online access to databases. Moreover, how can academic libraries meet increasing user demands for more database access and services when their resources are not increasing?

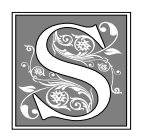

ince CD-ROM database products first emerged in academic libraries in 1986, they have proliferated and so too have studies investigating this technology. However, a literature review revealed that most articles on CD-ROM use are limited in scope, focusing on a single database or a single issue, and involve only a limited population of users. The most common method of inquiry is the survey instrument. Although academic li- braries have invested heavily in technology and online services for the past ten years, the demand for more end-user computer services continues to increase. Along with the new technology, it appears that library users expect more assistance and training. Until recently, academic libraries continue to purchase CD-ROM products at a growing rate without first carefully evaluating the effectiveness of their current services. As academic libraries continue to face finan-

Cheryl A. McCarthy is an Assistant Professor in the Graduate School of Library and Information Studies at the University of Rhode Island; e-mail: chermc@uriacc.uri.edu. Sylvia C. Krausse is Professor and Chair of Public Services at the University of Rhode Island; e-mail: skrausse@uriacc.uri.edu. Arthur A. Little is a doctoral student at the University of Rhode Island who provided statistical data analyses and input to the design and methodology section; e-mail: alit1837@uriacc.uri.edu. 
cial constraints and staff shortages in the 1990s, how are they going to respond to the increasing demands of users in light of decreasing resources?

A recent study on effective library use at the University of Rhode Island (URI) revealed that students most frequently request better availability of materials and more assistance and training, especially on CD-ROM databases. ${ }^{1}$ Thus, this study is a follow-up investigation of students' expectations, effectiveness, and satisfaction with CD-ROM services at the URI Library.

During spring semester 1995, training sessions on CD-ROM databases were provided for URI students in Writing 101. The goal of the training was to produce effective and independent searchers on CD-ROM products. Students in these sessions were surveyed to assess the training they received. In addition, all users of CD-ROM databases at the URI Library during the month of April 1995 were asked to complete a survey to evaluate their needs, skills, and satisfaction using CD-ROM products and services. All responses were voluntary and anonymous.

\section{The CD-ROM Environment at the University of Rhode Island Library}

The process of acquiring CD-ROMs at URI began in 1987 as a joint purchase of Compact Disclosure with the Business School. Because of the popularity of this first CD-ROM, the reference librarians evaluated the library's DIALOG and BRS online services in order to justify the purchase of additional CD-ROM databases. After an evaluation of user statistics, it became apparent that the most popular and frequently requested online databases were MEDLINE, PsycLit, and ERIC. Based on these findings, a CDROM policy was created that addressed the priorities for purchasing reference CD-ROM databases. The reference librarians recommended the purchase of MEDLINE, PsycLit, ERIC, the Government Documents Catalog Service, MLA, and UMI's Periodical Abstracts as the first tier of CD-ROM databases.

During the following three years, the library gradually added four of the Wilson titles and additional workstations. In 1990, LANTASTIC was acquired and ten workstations were networked. The popularity of the CD-ROMs skyrocketed and students queued up to use them, even refusing to use the print versions. Multiple-user subscriptions had to be purchased to ease the congestion. A declining budget was stretched to purchase more hardware and multiple-user licenses.

In 1992, Sylvia Krausse wrote a grant proposal to equip a CD-ROM room with appropriate workstations and networked printers. The Champlin Foundations granted the proposal and provided funding for a local area network (LAN), connecting eighteen workstations with two servers and several CDROM towers. The library added more subscription databases, namely UMI's Newspaper Abstracts, Dissertation Abstracts, Newsbank, CINAHL, PAIS, Biological Abstracts, Engineering Index, Textile Technology Digest, America: History and Life, Historical Abstracts, and Moody's International.

In the fall of 1993, a LAN of CD-ROM workstations was officially connected; and by the spring of 1995, there were twenty-two CD-ROM databases networked using LANTASTIC. Ever since the first tier of CD-ROMs was acquired, statistics showed a steady increase in CDROM use. With the addition of the CDROM room and more requests for assistance, it became apparent that during the busiest hours of the day full staffing of the CD-ROM room was a necessity. With the opening of the CD-ROM room, students were hired between the hours of eleven in the morning and two in the afternoon. Because of the pressing demand for assistance in the room, one hour was added each semester until the CD-ROM room was fully staffed from ten in the 
morning until five in the afternoon, and again from six to nine in the evening during the week and on the weekend during the majority of the hours that reference service was provided.

In addition to personal assistance, every two workstations share an instructional notebook that contains one-page instructional guides by database as well

\section{Thus, general hands-on training sessions were offered in addition to the instruction during the regular bibliographic instruction classes.}

as by interface (e.g., Silverplatter, UMI, or Wilson). During the times that the room is not staffed, patrons either use these binders or go to the Reference Desk for additional help. It was soon evident that although users want assistance or instruction at point of use, the librarians also would need to offer additional training sessions in a classroom setting to larger groups to ease the demand in the CD-ROM room for one-on-one instruction. Thus, general hands-on training sessions were offered in addition to the instruction during the regular bibliographic instruction classes.

\section{Literature Review}

A survey of the literature reveals that the introduction of CD-ROMs in academic libraries has created an increase in demand for point-of-use assistance by the reference staff. With the technology explosion in libraries, the number of workstations, databases, and queries for assistance have multiplied in reference departments, but the number of staff has not increased accordingly. ${ }^{2}$ Moreover, the increases in CD-ROM products and the on-demand requests for training may be affecting the quality of reference services and staff morale, and may even cause staff burnout. ${ }^{3}$ In one research study on bibliographic instruction methods on CD-ROM data- bases, Dorothy F. Davis offered a practical solution to alleviate staff stress: "librarians must provide more effective group instruction or offer self-instructional alternatives."

Vendors, however, have promoted their products for end users, claiming little or no assistance is needed from professional staff. Although these products are relatively easy for end users, most patrons are not familiar with the multitude of subject-specific databases and/ or do not know which one(s) to select. Students faced with multiple databases are often overwhelmed by the many choices and need to seek help. CD-ROM products, however, do offer a cost-effective way for users to search databases compared to mediated online searching, which is usually costly and time-consuming. Thus, several studies have addressed the increased demands for assistance using CD-ROMs and identified the impact of CD-ROM products or services on libraries and staff. ${ }^{5}$

Other CD-ROM studies have evaluated specific training or bibliographic instruction programs in academic libraries. ${ }^{6}$ Some studies have investigated user perceptions about, or satisfaction with, using specific CD-ROM products. ${ }^{7}$ On the questionnaires used to assess CDROM use, most respondents revealed a high degree of user satisfaction. A study titled "Value-added Bibliographic Instruction" by Stanley D. Nash and Myoung Chung Wilson showed that although students were satisfied with their searches, an analysis of their searches revealed that more than one-third of the citations retrieved by students were useless or inappropriate for their topics. ${ }^{8}$

Although these studies contributed to a broader understanding of user needs and satisfaction with CD-ROMs, professional concerns continue to grow about these products. Without a standard for CD-ROM database products, each vendor develops a unique interface system, code, terminology, and search strategy 
that is not easily transferred from one to the other by users. Students are often confused about which databases to use in order to find appropriate sources for their research needs. Although some interfaces provide easier search strategies, many undergraduates are unaware of specialized subject databases and are familiar only with one general CD-ROM database from their high school or public library experiences. Furthermore, they are unfamiliar with the differences in vendor or interface systems, serials indexed, or thesauri. The literature review provided insights from numerous studies addressing some of these concerns related to CD-ROM use and instruction, but none of the investigations assessed the total CD-ROM environment in an academic library.

One significant investigation, however, assessed the CD-ROM environment (fifteen commercial products networked) at the University of North Carolina at Chapel Hill and provided the most broad-based perspective. ${ }^{9}$ The goal of that study was to evaluate the CD-ROM "system's success to gather information that would enable the staff to evaluate and improve the service." ${ }^{10}$ Although an electronic survey was used, apparently no further inquiry was performed to assess either user training or satisfaction with CD-ROM products and services.

\section{Utility of Study}

What follows, therefore, is an attempt to build on these previous studies by evaluating the whole CD-ROM environment at one academic library at URI. The goal of this study is to determine users' preferences and needs, their confidence in searching, the effectiveness of their training, and their overall satisfaction with CD-ROM services. The authors hope that this study will help library staff to evaluate their CD-ROM environment and to plan improvements in the total electronic delivery of databases.

\section{Design and Methodology}

This study is the result of a collaboration between the principal investigators, Cheryl McCarthy and Sylvia Krausse. Arthur Little, a doctoral student, performed statistical analyses of the data from the questionnaires and provided input to the Design and Methodology section.

This study was designed as a needs assessment for users of CD-ROM databases at the URI Library. After an initial study indicating student demands for more instruction using CD-ROMs, the reference librarians initiated a series of handson CD-ROM training sessions for freshmen in Writing 101 classes in the library's new electronic classroom (ECL). ${ }^{11}$ A survey was designed to evaluate both $C D$ ROM needs and services for students in CD-ROM training classes, as well as for a sample of students using the CD-ROM services during the spring of 1995 .

The specific research objectives for this study were:

1. to determine users' preferences in searching CD-ROM databases versus print indices;

2. to assess users' confidence in their searching skills;

3 . to identify what users need to become more effective searchers on CDROMs;

4. to assess effectiveness of CD-ROM training sessions;

5. to assess users' satisfaction with CDROM services.

An eleven-item questionnaire addressing these objectives was pretested and revised to eliminate ambiguity in language and meaning. This process provided both a reliability and a validity check to ensure that the survey items reflected the research objectives of the principal investigators. A total of 750 questionnaires were distributed - to both the students in the Writing 101 classes who attended the training and everyone who used the CD-ROM facility during the month of April 1995. A return box was 
provided at the CD-ROM desk, and 489 completed questionnaires were returned. No attempt was made to survey either nonusers or users of print indices in other locations.

\section{Data Analysis}

Analyzing the questionnaire data, using both quantitative and qualitative measures, provided the researchers with an in-depth interpretation of the five research objectives. Quantitative statistical methods were used to evaluate the numerically measurable survey variables. These included demographic and usage information, database preference infor-

\section{The principal investigators also made unobtrusive observations of CD-ROM users.}

mation, and three five-point Likert scales to measure perceived CD-ROM confidence levels (question five), satisfaction levels (question eleven), and effectiveness of training (question ten-applied to Writing 101 groups). Qualitative means were used to analyze open-ended followup queries to the Likert scale questions. These follow-up items were phrased in the form of "Please explain" or "Why?" Content analysis was chosen as one way to analyze these data because of its advantages "in making inferences by objectively and systematically identifying specified characteristics of messages" into categories. ${ }^{12}$ One advantage in using content analysis is that specified characteristics occurring in open-ended questions can be quantitatively identified, studied, and rank-ordered to assess common traits or problems. By employing both qualitative and quantitative procedures in content analysis, insights can be gleaned from both what is seen and not seen, and from what is reported and not reported. Moving between the quantitative statistical analysis and the qualitative content analysis, the investigators gained insights into the full meaning of the data. Techniques for the coding, displaying, and verifying of data are adapted from recommendations by Ole Holsti. ${ }^{13}$ The principal investigators also made unobtrusive observations of CDROM users. Thus, a process of triangulation was used to achieve "intersubjectivity" and full insight into the meaning of the data. ${ }^{14}$ Furthermore, the investigators were able to draw inferences into students' effectiveness in and satisfaction with training and CDROM services.

The quantitative data from the 489 completed questionnaires were converted into machine-readable form and imported into the statistical analysis package SPSS/PC+. The data were then tabulated and examined for accuracy and for "out-of bounds" conditions, which were then corrected. For example, twenty of the questionnaires were completed by nonstudents, so they were removed from the analysis. The responses from the fivepoint confidence scale were collapsed into the following three categories so that a two-way contingency table using this variable would have no expected frequency below five for any cell: "Less Confident" combined responses one and two; "Moderately Confident" represents response three; and "More Confident" combined responses four and five. ${ }^{15}$ Prior to gathering these data, the investigators set their alpha level to .05 to reduce the probability of a Type I error. In order to test the degree of association between preferences for the CD-ROM databases and their equivalent print indices, the number of responses for each database was summed. These sets of values were then ranked for each medium and a Spearman's Rank Order Correlation Coefficient (Spearman's Rho, $r_{s}$ ) between the two sets of ranked databases was calculated using the formula $r_{s}=1-\left(\left(6 D^{\wedge} 2\right) /\right.$ $\left.\left(\mathrm{N}\left(\mathrm{N}^{\wedge} 2-1\right)\right)\right) \cdot{ }^{16}$

The principal investigators used content analysis to code responses from the 
open-ended questions and observations. The notes were coded into categories adapted from the responses. Categories were collapsed to combine similar comments into broader subject areas. To ensure intercoder reliability, data coded by one principal investigator were verified by the other.

\section{Interpretation of Data User Profile}

Of the 489 users, 79 percent were undergraduate students, 17 percent were graduate students, and 4 percent were faculty, staff, or other. Of the undergraduates, 50 percent were upper level and 29 percent were lower level. Thus, the survey respondents reflect the overall university population of approximately 80 percent undergraduates, who were the intended target audience for this study. When asked if this was the first time using CD-ROM databases this academic

\begin{tabular}{|lrc|}
\hline \multicolumn{3}{|c|}{ TABLE 1 } \\
Survey Participants, Reported \\
Academic Status \\
\hline \hline \multicolumn{3}{|c|}{ Question 1: “Please mark your } \\
stacademic below.” \\
\multicolumn{1}{|c|}{ N } & Percent \\
\hline Undergrad.-Yr. 1 & 110 & $22.49 \%$ \\
Undergrad.-Yr. 2 & $\underline{33}$ & $\underline{6.75}$ \\
Undergrad./lower total & 143 & 29.24 \\
Undergrad.-Yr. 3 & 98 & $20.04 \%$ \\
Undergrad.-Yr. 4 & 126 & 25.77 \\
Undergrad.-Yr. 5 & $\underline{20}$ & $\underline{4.09}$ \\
Undergrad./higher total & 244 & 49.90 \\
Graduate-MA/MS & 57 & $11.66 \%$ \\
Graduate-Ph.D. & $\underline{25}$ & $\underline{5.11}$ \\
Graduate students total & 82 & 16.77 \\
& & \\
Faculty & 5 & $1.02 \%$ \\
Staff & 6 & 1.23 \\
Other & $\underline{9}$ & $\underline{1.84}$ \\
Nonstudent total & 20 & 4.09 \\
\hline Total & 489 & $100 \%$ \\
\hline
\end{tabular}

year, 16 percent indicated yes, compared to 71 percent who said they had used the databases between two and ten times this academic year and 29 percent who had used them more than eleven times. Thus, with the exception of the freshmen in Writing 101, most students surveyed were experienced CD-ROM users, having used them previously this year (see tables 1 and 2).

\section{User Preferences in Searching CD-ROMs}

To determine users' needs and preferences in searching CD-ROM databases versus print indices, the questionnaire asked them to identify the CD-ROM databases or print indices most frequently used from the list of the twenty-two versions. Table 3 shows the rank order of databases and print indices selected and the Spearman's Rho comparing the strength of the relationship between the CD-ROM version and the print version. The Spearman's Rho shows a high level of agreement between the two database sets indicating a clear pattern of similar database preferences, which is independent of format. It is also curious to note

\begin{tabular}{|c|}
\hline TABLE 2 \\
Survey Participants, Reported \\
CD-ROM Usage \\
\hline \hline
\end{tabular}

Question 2: "Is this the first time you have used the CD-ROM databases?"

\begin{tabular}{lcc} 
& N & Percent \\
\hline Yes & 77 & $15.75 \%$ \\
No & 412 & 84.25 \\
\hline Total & 489 & $100 \%$
\end{tabular}

Question 3: "How many times have you used the CD-ROM databases this year?"

\begin{tabular}{lrl} 
& $\mathrm{N}$ & Percent \\
\hline 2-5 times & 165 & $40.05 \%$ \\
6-10 times & 128 & 31.07 \\
11-20 times & 62 & 15.05 \\
21 or more & 57 & 13.83 \\
\hline Total & 412 & $100 \%$ \\
\hline
\end{tabular}




\begin{tabular}{|c|c|c|c|c|c|}
\hline Rank Or & rder & $\begin{array}{r}\text { TAB } \\
\text { Prefe } \\
\end{array}$ & $\begin{array}{l}\mathrm{E} 3 \\
\text { ence of Databases }\end{array}$ & & \\
\hline $\begin{array}{l}\text { Question } 4 \text { presented a list of } 22 \\
\text { were asked to indicate which they } \\
\text { database by type of medium and } \\
\text { Coefficient }\left(\boldsymbol{r}_{s}\right) \text { was computed to } \\
p<.001 \text {. }\end{array}$ & $\begin{array}{l}C D \\
\text { y use } \\
\text { then } \\
\text { find }\end{array}$ & $\begin{array}{l}\text { ROM a } \\
\text { d most } \\
\text { rank o } \\
\text { the ass }\end{array}$ & $\begin{array}{l}\text { d print databases, and the partici } \\
\text { ften. The responses were summed } \\
\text { dered. A Spearman Rank Correlati } \\
\text { ciation between the format: } \boldsymbol{r}_{s}=+\end{array}$ & $\begin{array}{l}\text { pan } \\
\text { for } \\
\text { ion } \\
.95\end{array}$ & $\begin{array}{l}\text { ts } \\
\text { each } \\
4,\end{array}$ \\
\hline CD-ROM Database & $\mathrm{N}$ & Rank & Print Database & $\mathrm{N}$ & Rank \\
\hline Social Sciences Index & 104 & 1 & Periodical Abstracts & 28 & 1 \\
\hline Periodical Abstracts & 89 & 2 & Social Sciences Index & 23 & 2 \\
\hline Humanities Index & 81 & 3 & ABI Inform & 20 & 3 \\
\hline ABI Inform & 71 & 4.5 & Newspaper Abstracts & 19 & 4 \\
\hline PsycLit & 71 & 4.5 & PsycLit & 18 & 5 \\
\hline Newspaper Abstracts & 69 & 6 & ERIC & 16 & 6 \\
\hline Newsbank & 64 & 7 & Newsbank & 14 & 7 \\
\hline ERIC & 58 & 8 & Humanities Index & 13 & 8 \\
\hline Disclosure & 45 & 9 & Moody's International & 12 & 9 \\
\hline Moody's International & 43 & 10 & MLA & 11 & 10.5 \\
\hline Medline & 42 & 11 & Medline & 11 & 10.5 \\
\hline PAIS & 34 & 12.5 & Disclosure & 10 & 12 \\
\hline Biological Abstracts & 34 & 12.5 & Biological Abstracts & 9 & 13.5 \\
\hline MLA & 32 & 14 & PAIS & 9 & 13.5 \\
\hline Historical Abstracts & 27 & 15 & American History \& Life & 8 & 15 \\
\hline Dissertation Abstracts & 26 & 16 & Historical Abstracts & 7 & 16 \\
\hline Applied Science \& Tech. Index & 25 & 17 & Applied Science \& Tech. Index & 6 & 17 \\
\hline American History \& Life & 23 & 18 & Dissertation Abstracts & 4 & 18 \\
\hline CINAHL (Nursing Index) & 22 & 19 & CINAHL (Nursing Index) & 3 & 20.5 \\
\hline Biological \& Agricultural Index & 18 & 20 & Biological \& Agricultural Index & 3 & 20.5 \\
\hline Engineering Index (Compendex) & 13 & 21 & Engineering Index (Compendex) & 3 & 20.5 \\
\hline TTD ( Textiles) & 7 & 22 & TTD ( Textiles) & 3 & 20.5 \\
\hline
\end{tabular}

that students indicated using a print version of Disclosure, despite the fact that no print version exists.

The most frequently cited CD-ROM databases were similar to the print versions, revealing the top eight preferences as Social Sciences Index and Periodical Abstracts, closely followed by Humanities Index, ABI Inform, PsycLit, Newspaper Abstracts, Newsbank, and ERIC. Although the rank order was similar, the CD-ROM versions were cited at least three times more frequently than the print versions. For example, the number one CD-ROM database preferred was Social Sciences Index cited by 104 users, whereas the print version was the sec- ond highest preferred and cited by only twenty-three users. No print version was cited more frequently than its comparable CD-ROM version.

Furthermore, when users were asked which version they prefer, 85 percent chose the CD-ROM version compared to 11 percent for print, 4 percent checked both. The most frequently cited reasons given for CD-ROM preference by 77 percent of respondents include: easier to use, better subject access, faster and more efficient search process. An additional 8 percent of respondents preferring CDROMs gave the following reasons: can get a printout of sources, provides abstracts, can download, provides more 


\begin{tabular}{|c|c|c|}
\hline \multicolumn{3}{|c|}{$\begin{array}{c}\text { TABLE } 4 \\
\text { Expressed Preference for CD-ROM or } \\
\text { Print Database by Reason }\end{array}$} \\
\hline \multicolumn{3}{|c|}{$\begin{array}{l}\text { Question 5: "Which do you prefer, the CD-ROM version or } \\
\text { the printed version?" }\end{array}$} \\
\hline & $\mathrm{N}$ & Percent \\
\hline \multicolumn{3}{|l|}{ Prefer CD-ROM } \\
\hline Faster, easier, more efficient, better access & 213 & $77.46 \%$ \\
\hline Features: printout, download, abstracts, currency & 21 & 7.64 \\
\hline Don't know print source exists & 0 & 0 \\
\hline \multicolumn{3}{|l|}{ Prefer Print } \\
\hline Better for research, find more, has more dates & 16 & 5.81 \\
\hline Saves time, easier to use & 13 & 4.73 \\
\hline Don't know how to use CD-ROM version & 0 & 0 \\
\hline \multicolumn{3}{|l|}{ Prefer Having Both } \\
\hline $\begin{array}{l}\text { Both useful, easier to understand, includes } \\
\text { more dates }\end{array}$ & 12 & 4.36 \\
\hline Total & 275 & $100 \%$ \\
\hline
\end{tabular}

progresses by collapsing and labeling confidence levels one and two as "Less Confident," labeling response three as "Moderately Confident," and combining and labeling levels four and five as "More Confident." The majority of students indicated that they are confident in searching, with 71 percent of lower-level undergraduates, 82 percent of upper-level undergraduates, and 83 percent of graduate students expressing moderately and more

recent dates, and the print source unknown. On the other hand, 11 percent of respondents indicate that they like print sources better. They offered the following reasons: like hard copy, can find more items in print, CD-ROM misses items, easier and faster to search print, and do not know how to use the CD-ROM version. Slightly more than 4 percent of users chose both versions, citing that CDROMs and print indices are both valuable and useful for research and that combined they include more dates. A couple of users stated they had no preference (see table 4).

\section{User Confidence in Searching}

CD-ROM users were asked to rank their level of confidence on a Likert scale, where one equaled "Not at All Confident" and five equaled "Extremely Confident." It is not surprising to note that lower-level undergraduate students are less confident in using CD-ROMs whereas upper-level undergraduate and graduate students are more confident. Table 5 reveals the increase in user confidence as the students' class level confident. It is clear from table 5 that as students progress in class level through college and have more experience searching, their confidence level also increases when searching CD-ROM databases.

\section{User Needs to Become More Effective Searcher}

When users were asked "What more do you need to know to help you become more effective at searching CD-ROMs?" student responses were rank-ordered as "How to develop a search strategy," "How to choose the right CD-ROM database," "How to use the various software interfaces," and "How to limit search" (see table 6). When observing stu-

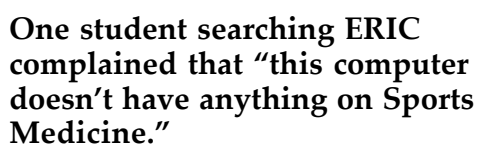

dents using CD-ROMs, one of the most frequently asked questions was "Which one (database) do I use?" Some students appear to search the databases randomly 


\begin{tabular}{|c|c|c|c|c|c|}
\hline \multicolumn{6}{|c|}{$\begin{array}{c}\text { TABLE } 5 \\
\text { Contingency Table_-“Confident" by "Academic Status" }\end{array}$} \\
\hline \multicolumn{6}{|c|}{$\begin{array}{l}\text { Question 6: "How confident are you about your searching skills on the CD-ROM } \\
\text { databases you use most often?" }\end{array}$} \\
\hline & & $\begin{array}{l}\text { Undergrad. } \\
\text { Lower }\end{array}$ & $\begin{array}{l}\text { Undergrad. } \\
\text { Higher }\end{array}$ & $\begin{array}{c}\text { Grad. } \\
\text { MA-Ph.D. }\end{array}$ & $\begin{array}{l}\text { Row } \\
\text { Total }\end{array}$ \\
\hline \multirow{5}{*}{$\begin{array}{l}\text { Less } \\
\text { confident }\end{array}$} & Observed f & 25 & 32 & 11 & 68 \\
\hline & Expected f & 17.77 & 37.17 & 13.07 & $20.42 \%$ \\
\hline & Row \% & $36.76 \%$ & $47.06 \%$ & $16.18 \%$ & \\
\hline & Column \% & $28.74 \%$ & $17.58 \%$ & $17.19 \%$ & \\
\hline & Total \% & $7.51 \%$ & $9.61 \%$ & $3.30 \%$ & \\
\hline \multirow{5}{*}{$\begin{array}{l}\text { Moderately } \\
\text { confident }\end{array}$} & Observed f & 40 & 79 & 18 & 137 \\
\hline & Expected f & 35.79 & 74.88 & 26.33 & $41.14 \%$ \\
\hline & Row \% & $29.20 \%$ & $57.66 \%$ & $13.14 \%$ & \\
\hline & Column \% & $45.98 \%$ & $43.41 \%$ & $28.13 \%$ & \\
\hline & Total \% & $12.01 \%$ & $23.72 \%$ & $5.41 \%$ & \\
\hline \multirow{7}{*}{$\begin{array}{l}\text { More } \\
\text { confident }\end{array}$} & Observed f & 22 & 71 & 35 & 128 \\
\hline & Expected f & 33.44 & 69.96 & 24.60 & $38.44 \%$ \\
\hline & Row \% & $17.19 \%$ & $55.47 \%$ & $27.34 \%$ & \\
\hline & Column \% & $25.29 \%$ & $39.01 \%$ & $54.69 \%$ & \\
\hline & Total \% & $6.61 \%$ & $21.32 \%$ & $10.51 \%$ & \\
\hline & Column & 87 & 182 & 64 & 333 \\
\hline & Total & $26.13 \%$ & $54.65 \%$ & $19.22 \%$ & $100 \%$ \\
\hline \multirow{2}{*}{\multicolumn{2}{|c|}{$\begin{array}{r}\text { Chi-square (Pearson) } \\
\text { Min. expected f }\end{array}$}} & 15.67 & $(\mathrm{df}=4)$ & $\mathrm{p}=.0035$ & \\
\hline & & 13.07 & & & \\
\hline
\end{tabular}

without either developing a search strategy or identifying what type of database they need. When they are unable to find their topic in one database, they search another until they are frustrated and ask for help. One student searching ERIC complained that "this computer doesn't have anything on Sports Medicine." It appears to the investigators that he lacked an understanding of the subject databases and blamed the computer. Thus, as they increase the number of databases, academic librarians also will need to educate students on the types of information found in each specialized database and how to search it, so that the students will use the appropriate database and find relevant sources for their research needs.

Other research studies have shown, and reference librarians have confirmed, that what patrons want most is hands- on assistance with searching at point of need, especially when using multiple

\begin{tabular}{|lr|}
\hline \multicolumn{2}{|c|}{ TABLE 6 } \\
Participants' Perceived Needs to \\
Being More Effective at Searching \\
\hline \hline Question 7: "What more do you need to \\
know to be more effective at searching \\
CD-ROMs?" \\
How to: \\
\hline Develop a search strategy \\
Choose the right CD-ROM database & 155 \\
Use the software interfaces & 154 \\
Limit search (by year, language, etc.) & 154 \\
Design \& modify search procedures & 142 \\
Save search results to floppy disk & 131 \\
Use language, keywords, thesaurus & 117 \\
Use AND, OR, \& NOT operators & 98 \\
Use the equipment & 86 \\
\hline
\end{tabular}


CD-ROM databases. When users were asked in question 8 what types of training they would like, the rank-ordered responses were: personal assistance from reference staff, hands-on workshop, online Help screen, and printed guidelines. The least frequently desired item was lecture/demonstration (see table 7).

It is not surprising that patrons want help at the point of need. Ironically, personal assistance at point of need is the most costly, most time-consuming, and most demanding on reference staff. Some studies indicate that these new demands are leading to reference staff burnout, yet it is the item most desired by students. Users' attitudes seem to suggest that they want immediate gratification and onestop shopping when using CD-ROMs. Students complain that they must perform several steps including checking citations with serial holdings and retrieving journals on microform or hard copy. They would prefer full text of articles on CD-ROM in addition to citations. The results confirm the expectation that when it comes to using electronic databases, users find more citations and demand more resources, faster delivery, and more hands-on assistance.

\section{Effectiveness of CD-ROM Training Sessions}

From the Writing 101 classes that attended lecture/demonstration sessions

\begin{tabular}{|lr|}
\hline \multicolumn{2}{|c|}{ TABLE 7 } \\
Participants' Preferred \\
Types of Training \\
\hline \multicolumn{2}{|c|}{ Question 8: “What types of training } \\
would you like to have in order to \\
become an effective searcher?” \\
& $\mathbf{N}$ \\
\hline & 198 \\
Personal assistance from staff & 184 \\
Hands-on workshop & 141 \\
Online Help screen & 131 \\
Printed guidelines & 43 \\
Lecture/demonstration &
\end{tabular}

early in the spring semester of 1995, five instructors decided to return in April, when the new ECL opened, for handson instruction on how to use CD-ROMs. The ECL is equipped with fifteen student workstations and one teacher station with a 42-inch monitor. The instructors and students were introduced to four Wilson CD-ROM databases: Social Sciences, Humanities, Applied Science and Technology, and Biological and Agricultural Index. The purpose of the session was to enable students to become more effective searchers. Of the eighty-one students, twenty students indicated the training was less than effective, thirtyseven students indicated it was moderately effective, and twenty-four students felt it was highly to extremely effective in helping them search (see figure 1).

When asked to explain their comfort levels after the training session, students offered a variety of responses. Their reasons were split, with twenty-nine students commenting positively and twenty-eight commenting negatively. The positive responses indicative of comfort level with training included: easier to understand this database, feel comfortable with CD-ROMs, know how to search, clear explanation, good demonstration, easier to use, helpful. The negative comments indicative of discomfort after training included: still need to know how to use CD-ROMs, need to know terms to search, still confused, too much information, and need hands-on training to use the computer.Although the majority of students felt more comfortable after the training, at least one-quarter of the students still needed and wanted more training with hands-on computer use. One can infer that one hour of training is not enough, especially considering the fact that students in each class have varying levels of computer expertise. When teaching new computer skills, learners need to be very familiar with the keyboard and have several hands-on sessions in order to master the skills presented. This 


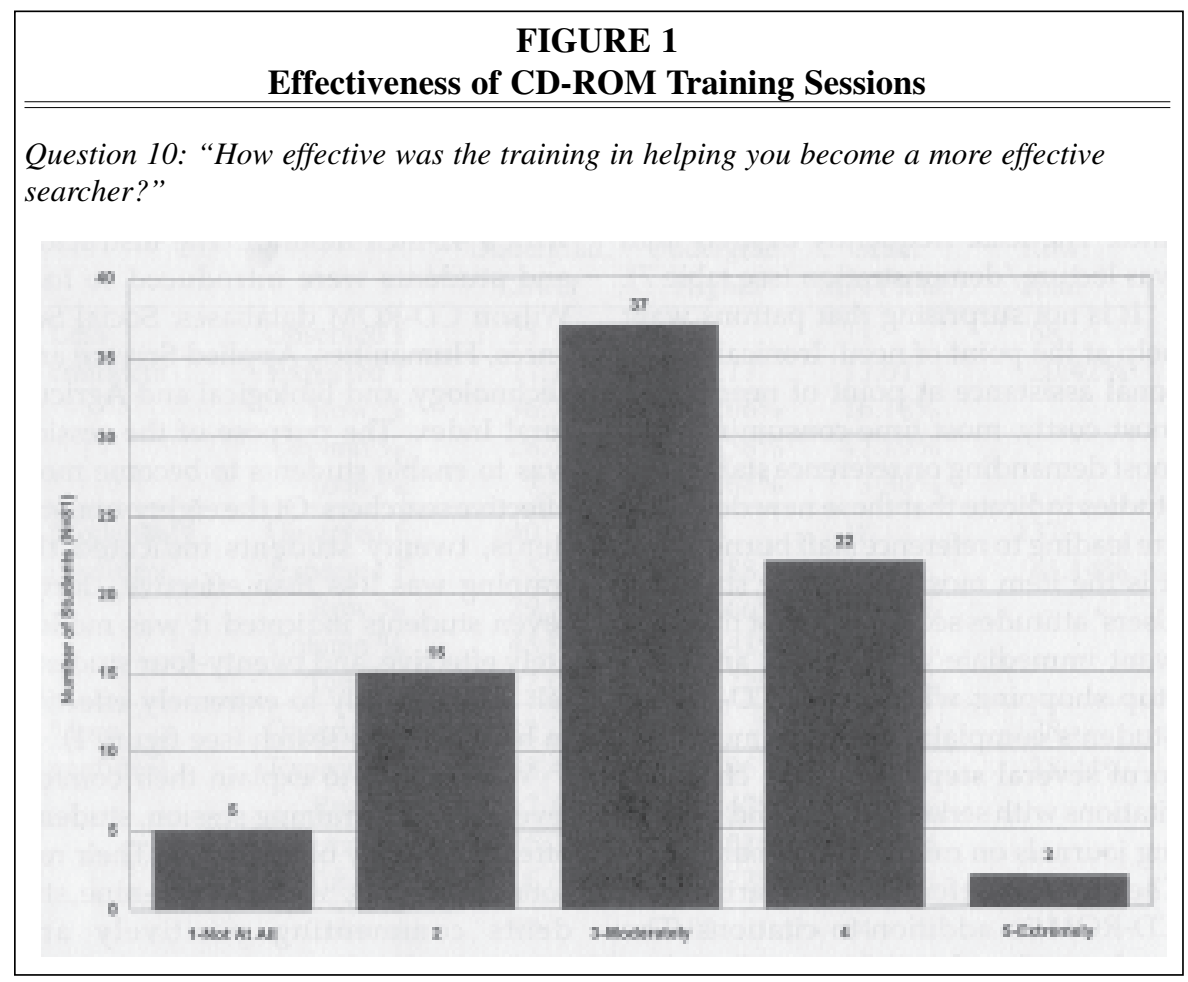

methodology is consistent with the users' preference for either personal assistance or hands-on workshops over the lecture/ demonstration method. Thus, it appears that students know what they need in order to become more effective searchers, and they expect training and assistance in academic environments.

\section{Overall User Satisfaction with CD-ROM Services}

Users of URI's CD-ROM databases were overwhelmingly positive when asked "How satisfied are you with the CDROM services?" Ninety-three percent indicated they are moderately to extremely satisfied, whereas only 7 percent indicated dissatisfaction. Figure 2 confirms other studies revealing that CD-ROM users are mostly satisfied with products and services with 284 out of 305 students moderately to extremely satisfied (see figure 2 ).
Although 93 percent said they were satisfied, only about 50 percent gave positive comments in response to this question. Negative comments included complaints about services, equipment or systems hassles, and suggestions for improvements to CD-ROM services. For evaluating and planning future resources and services, the comments are most useful for the reference staff.

When asked to explain their level of satisfaction, 141 users commented. Comments were collapsed into four categories: positive, negative, equipment hassles, and a wish list. The following views were categorized as positive comments: very helpful staff; someone is available to help; good variety of databases; good access to information; great tool for research; easy to use; convenient, fast, efficient, and effective services. The following opinions by thirty-two users were coded as 


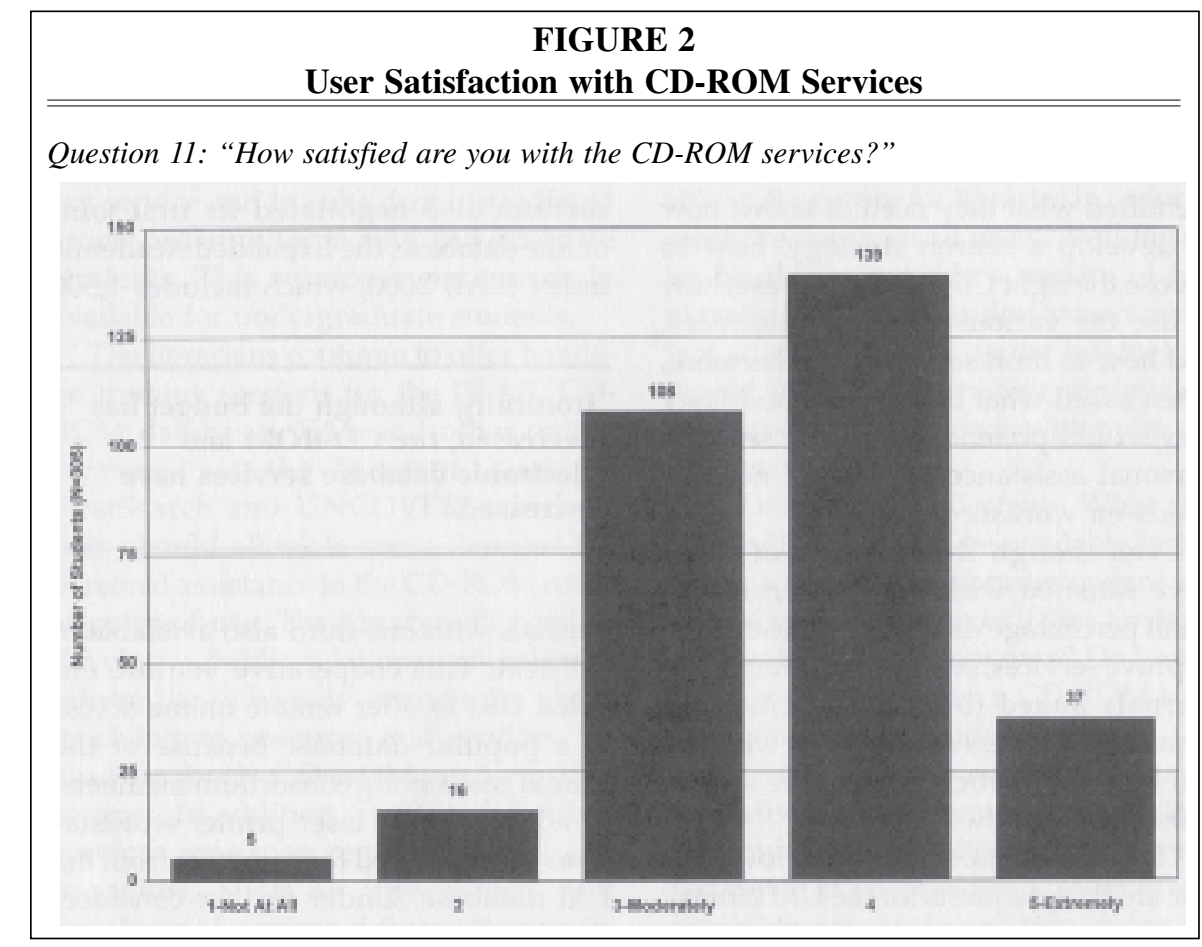

negative comments: still need help; confusing or overwhelming; hard to know what is available; difficult to understand system, terms, or what database to use; sometimes staff is too busy to help; difficult to find periodicals after using CD-ROM. In addition, twelve users complained of equipment hassles: the system is too slow, computers are not always available, need more terminals, need more printers, need larger space, CD-ROMs slow and temperamental, and problems with the printer.

Perhaps the most valuable comments were suggestions for improvements offered by twenty-six users. A rank order of the most frequently requested items include:

1. need more periodicals to match citations;

2. CD-ROMs should note whether URI has journal;

3. need journals on shelf;

4. make more staff available to help with searches;
5. provide full-text access on CDROMs;

6. offer remote access to CD-ROM databases;

7. offer full-text databases;

8. provide better print capability;

9. buy more CD-ROMs to provide better access to older materials;

10. buy more current materials;

11. sell disks in the library to download;

12. buy laser printers;

13. purchase Philosopher's Index and Art Index on CD-ROM;

14. require mandatory learning sessions on CD-ROMs.

\section{Conclusions and Recommendations}

Users of CD-ROMs at URI clearly indicated their preferences for CD-ROM services: CD-ROMs over print indices, online remote access to CD-ROM databases, more access to journals cited, and more training or assistance searching. Moreover, the majority of students feel 
confident searching, although upperlevel undergraduate and graduate students expressed a higher confidence level than lower-level undergraduates. To become more effective searchers, students identified what they need to know: how to develop a search strategy, how to choose the right CD-ROM database, how to use the various software interfaces, and how to limit searches. Furthermore, when asked what training methodology they would prefer, the majority selected personal assistance at point of need or hands-on workshops.

Even though the majority of users were satisfied with current services, a small percentage did offer suggestions to improve services, such as providing more journals linked to CD-ROM citations, more online access to databases with full text of journal articles, and more staff to assist with searches.

The question now remains: How realistic are these requests for the URI Library or other academic libraries where budgets are shrinking and staff is decreasing? In January 1996, the library was forced again to cancel more journals; approximately $\$ 200,000$ worth of journals were eliminated and future increases in projected revenue will be insufficient to pay for projected inflationary increases on the library's serial subscriptions. Therefore, further reductions in the number of subscriptions is likely in the future. Ironically, although the budget has decreased, the CD-ROM and electronic database services have increased - but at the cost of eliminating other resources, especially print indices that are available in CD-ROM or online format.

One answer to dwindling budgets and increasing demands for more electronic access is more cooperation and shared resources. Since the formation of a consortium of five academic libraries in Rhode Island, HELIN (Higher Education Library Information Network), the URI Library has moved one step further in that direction. The OPAC called HELIN was purchased by the consortium consisting of the University of Rhode Island, Rhode Island College, Community College of Rhode Island, Providence College, and Roger Williams University. The consortium also negotiated its first joint online database, the Expanded Academic Index (EAI) 2000, which includes 1,500

\section{Ironically, although the budget has decreased, the CD-ROM and electronic database services have increased.}

journals with one-third also available in full text. This cooperative venture enabled URI to offer remote online access to a popular database because of the shared cost among consortium members. In addition, two laser printer workstations are dedicated for printouts from the EAI database. Under further consideration is a networked print solution for all electronic databases, including the OPAC.

With the added ability to search the EAI database remotely, congestion and requests for assistance in the CD-ROM room have been reduced. Because of the popularity of remote access to databases, the HELIN consortium continues to negotiate access to other resources available from Internet providers. After a threemonth trial period in early 1996, several databases are now also offered via FirstSearch. As a member of other consortia, URI also acquired Britannica Online and the Engineering Village.

With more demand for online access to databases and full-text journal articles, the library will need to continue to evaluate which services are essential and which resources are to be eliminated. Innovative ways to fulfill these demands have to be provided. Current library policy calls for the elimination of duplicate resources. Thus, some CD-ROM databases and print indices would be can- 
celed if they were also provided by the comprehensive database EAI. To ease the loss of canceled journals, the library also purchased UNCOVER's customized gateway to provide effective document delivery service and to subsidize unmediated article ordering for faculty and graduate students. This service is not currently available for undergraduate students.

The librarians continue to offer handson training sessions for the OPAC, CDROM databases, EAI, and other online services via the Internet, such as FirstSearch and UNCOVER, which in turn should alleviate some demand for personal assistance in the CD-ROM room at point-of-use. The library will need to develop a public relations campaign to inform the university community about its changing resources and services, including both CD-ROM and on-line sources. In addition, staffing the public services area may require creative approaches, such as internships and reshifting of personnel from other units. Furthermore, academic libraries need to rethink reference services as advocated by David W. Lewis's call for organizational change in academic libraries. ${ }^{17}$

\section{Future Implications}

CD-ROM databases were much in demand for the past decade, and they continue to be a popular choice among students and researchers in academic libraries. With the expansion of database access by Internet providers, however, there is an increasing demand for more online remote access to full-text databases via Internet providers. It appears obvious that academic libraries are currently wrestling with the following unresolved questions regarding electronic access to databases:

1. Cost: Can libraries afford to provide remote access to electronic databases with more subscriptions and more site licenses while maintaining and increasing CD-
ROM networks? Should librarians abandon CD-ROM networks in favor of remote access to databases via the Internet?

2. Medium: What formats will be available in the future for libraries in order to meet the demands of users? Will libraries be able to provide a variety of formats including duplication of resources? Is it advisable to rely on the Internet, or would it be more prudent to develop campus-based tape loads with more expensive equipment?

3. Long-range implications: What formats will or will not be available in ten years, and how can libraries ensure adequate archival resources if they are leasing services they do not own? Do libraries own the data when a CD-ROM subscription ends or vendors change?

4. Service: What changes will occur in the delivery of reference services? Will academic libraries offer more personal assistance at point of need, more intensive bibliographic instruction including hands-on training with new technologies, or more remote online services? Will librarians provide mediated online searching or electronic reference queries to help users with their online searches? Will libraries offer an amalgamation of services, including CD-ROM, tape loads, Internet, LAN, WAN, and print indices? Or will there be another unforeseen technological opportunity?

Academic libraries and librarians are at a crossroads and will need to choose what resources to offer, regardless of medium. Libraries will not be able to afford a full array of formats for all resources, and thus they will need to decide which resources and which media to offer in the future. Cooperative collection development and shared resources among libraries in consortia seem to be one of the best routes for academic libraries to take. 


\section{Notes}

1. Cheryl A. McCarthy, "Students' Perceived Effectiveness Using the University Library," College \& Research Libraries 56 (May 1995): 26-41.

2. David W. Lewis, "Making Academic Reference Services Work," College \& Research Libraries 55 (Sept. 1994): 445-56.

3. Charles R. Hixson, "CD-ROM and the Undergraduate: Reference and Instruction at Risk," Reference Services Review 21, no. 3 (fall 1993): 31-34.

4. Dorothy F. Davis, "A Comparison of Bibliographic Instruction Methods on CD-ROM Database," Research Strategies 11 (summer 1993): 156-63.

5. See Gillian Allen, "CD-ROM Training: What Do the Patrons Want?" RQ 30, no. 1 (fall 1990): 88-93; Susan K. Charles and Katharine E. Clark, "Enhancing CD-ROM Searches with Online Updates: An Examination of End-User Needs, Strategies, and Problems," College \& Research Libraries 51, no. 4 (July 1990): 321-28; Elaine C. Clever and David P. Dillard, "What Do CD-ROM Users Really Need?" Information Services and Use 11,. no. 3 (July 1991): 141-53; Hixson, "CD-ROM and the Undergraduate"; Trudi E. Jacobson, "All I Need Is in the Computer," Reference Librarian 38 (1992): 221-28; Deanna Nipp, "Back to Basics: Integrating CD-ROM Instruction with Standard User Education," Research Strategies 9, no. 1 (winter 1991): 41-47; Margaret Sylvia and Leigh Kilman, "Searching on CD-ROM in an Academic Environment," Computers in Libraries 11, no. 10 (Nov. 1991): 44-46.

6. See Kimberly Amato and Margaret W. Jackson, "CD-ROMs: Instructing the User," $C D$ ROM Librarian 5 (June 1990): 14-21; Caroline Blumenthal, Mary Jo Howard, and William R. Kinyon, "The Impact of CD-ROM Technology on a Bibliographic Instruction Program," College \& Research Libraries 54 (Jan. 1993): 11-16; Rebecca Bostian and Anne Robbins, "Effective Instruction for Searching CD-ROM Indexes," Laserdisk Professional 3 (Jan. 1990): 14-17; Nancy Broughton, Patricia Herrling, and Nancy McClements, "CD-ROM Instruction: A Generic Approach," CD-ROM Librarian 6 (Nov. 1991): 16-19; Gregory A. Crawford, "The Effects of Instruction in the Use of PsycLIT on Interlibrary Loan," RQ 31, no. 3 (spring 1992): 370-76; Davis, "A Comparison of Bibliographic Instruction Methods on CD-ROM Database"; Danise G. Hoover and Victoria Clayton, "Graduate Bibliographic Instruction in ERIC on CD-ROM," Behavioral \& Social Sciences Librarian 8. nos. 1-2 (1989): 1-12; Richard F. Kenny and Eileen Schroeder, "An Evaluation of a Training and Assistance Program for the CD-ROM Databases: Reflections on the Process," Reference Services Review 20, no. 2 (summer 1992): 41-48; Bruce Leach, "Computer-Based CD-ROM Tutorials-Providing Effective On-Demand Instruction," CD-ROM Professional 6 (July 1993): 113-14+; Ida B. Lowe, "Integrating CD-ROMs into Your Bibliographic Instruction Program," CD-ROM Professional 3 (Nov. 1990): 16-19; Patricia Lynn and Karen Bacsanyi, "CD-ROMs: Instructional Methods and User Reactions," Reference Services Review 17, no. 2 (summer 1989): 17-25; John Maxymuk, "Considerations for CD-ROM Instruction," CD-ROM Professional 4 (May 1991): 47-49.

7. Stanley D. Nash and Myoung C. Wilson, "Value-Added Bibliographic Instruction: Teaching Students to Find the Right Citations," Reference Services Review19, no. 1 (spring 1991): 87-92.

8. Ibid.

9. Tim Bucknall and Rikki Mangrum, "U-Search: A User Study of the CD-ROM Service at the University of North Carolina at Chapel Hill," RQ 31, no. 4 (spring 1992): 542-53.

10. Ibid., 542.

11. McCarthy, "Students' Perceived Effectiveness Using the University Library."

12. Ole R. Holsti, Content Analysis for the Social Sciences and Humanities (Reading, Mass.: AddisonWesley, 1969), 40.

13. Ibid., 30.

14. Abraham Kaplan, The Conduct of Inquiry (Scranton,: Chandler Pub., 1964).

15. Marija J. Norusis, SPSS/PC+4.0 Base Manual for the IBM PC/AT and PS/2 (Chicago: SPSS, Inc., 1990).

16. Wayne W. Daniel, Applied Nonparametric Statistics (Boston, Mass.: Houghton-Mifflin, 1978).

17. Lewis, "Making Academic Reference Services Work." 